\title{
Authorship Trends in the American Journal of Neuroradiology
}

$\mathbf{T}$ he authorship demographics in the American Journal of Neuroradiology (AJNR) have been changing with time. The clinical demands on neuroradiologists have increased recently. We sought to determine whether there has been a commensurate shift toward more nonradiologist, $\mathrm{PhD}$, multi-institutional, and funded articles being published in the AJNR. We assessed AJNR-published articles for each branch of neuroradiology (Brain, Spine, Head and Neck, Neurointerventional Radiology [NIR], and Pediatrics [Ped]) to determine changes in the authorship characteristics of those who publish in the AJNR across time. We predicted a shift toward multi-institutional, $\mathrm{PhD}$-driven research in all fields except NIR, due to increasing clinical demands on physician neuroradiologists and the need for large datasets for writing definitive articles.

We reviewed 3 months of $A J N R$ articles published during 1998, 2003, 2008, 2013, and 2018 and characterized the degrees and specialties of the first authors, funding status, institutional affiliations, and type of article to assess trends across time. Only original publications were included. A binary logistic model was fitted to the data to test the research hypothesis regarding the relationship between the likelihood that multi-institutional and radiology field, and funding were associated with MDs (compared with $\mathrm{PhDs}$ ).

Tables 1, 2, and 3 present the results of these analyses. Of the 367 original articles, a radiologist was the first author in 280 $(76.3 \%)$ articles, followed by neurosurgeons $(27,7.4 \%)$ and neurologists $(26,7.1 \%)$. Three hundred sixteen $(86.1 \%)$ articles were written by $\mathrm{MD}$ or $\mathrm{MD}-\mathrm{PhD}$ first authors. One hundred forty-five (39.5\%) articles were from multiple institutions; 115 articles (31.3\%) were mentioned as funded. Of the funded articles, 74 (64.3\%) were first-authored by MDs, and 41 (35.7\%), by nonMDs. MDs had a gradually decreasing trend of first authorship from $96.6 \%$ in 1998 to $72.0 \%$ in 2018 . Among MDs, radiologists contributed $80 \%$ of the original articles in 1998, which decreased to $66.7 \%$ in 2013 and increased back to $77.5 \%$ in 2018 . The regression model showed that multi-institutional studies were associated with MDs as first authors (OR $=6.5$; 95\% CI, 3.5911.77). Also, radiologists exceeded all other subspecialties $(\mathrm{OR}=$ 3.42; 95\% CI, 1.69-6.93) for MD authors.

http://dx.doi.org/10.3174/ajnr.A6463

\section{Characteristics of AJNR Authors}

By viewing trends in authorship, one can assess the state of the specialty in terms of academic output. In radiology, in which MDs and PhDs own considerable authorship space, these trends can reveal the evolution of research productivity. In a study by Emamzadehfard et $a{ }^{1}{ }^{1}$ the country of the first author's institution in published articles in AJNR issues from January 2016 to June 2018 was categorized by Brain, Head and Neck, Spine, NIR, and Ped sections. They concluded that contributions to the AJNR from non-US authors dominated in the NIR category, likely due to the more restrictive limitations of the FDA on new NIR devices in the United States compared with Europe. Authors from Asian countries contributed more to Head and Neck articles, likely due to the increased prevalence of thyroid and nasopharyngeal carcinomas as well as Epstein-Barr virus infections in Asia. Authors from European countries published more articles than those in Asian countries in Pediatrics, in part due to authoritative and prolific Italian experts in pediatric neuroradiology. The US prominence was foremost in the Spine, and authors from Canada dominated the non-US spine contributions. Overall, the contributions from non-US authors (55.9\%) to the AJNR exceeded those originating from the United States (44.1\%). ${ }^{1}$

\section{Trend Towards PhD Authorship}

Our results show a decline of MD authorship from $96.6 \%$ in 1998 to $72.0 \%$ in $2018(P=.003)$. What accounts for the shift away from $\mathrm{MD}$ first authorship to more $\mathrm{PhD}$-first authored AJNR articles in this time period? One possibility is the changing research environment for academic radiologists in the United States, who have taken on more clinical responsibilities, with consequent reduction of academic time, energy, and resources for research. Another factor may be the increasing challenge of obtaining research funding in the United States. Fang and Casadevall $^{2}$ documented the lack of academic support granted to American investigators, particularly compared with prior time periods. These findings are in line with our results, which showed the large role of $\mathrm{PhD}$ first authors who may benefit from greater resources for research and more funded time. 
Table 1: The distribution of first authors, degrees, institutions, funding, and fields across time

\begin{tabular}{|c|c|c|c|c|c|c|c|c|c|c|}
\hline & \multicolumn{2}{|c|}{1998} & \multicolumn{2}{|c|}{2003} & \multicolumn{2}{|c|}{2008} & \multicolumn{2}{|c|}{2013} & \multicolumn{2}{|c|}{2018} \\
\hline & Count & $\%$ & Count & $\%$ & Count & $\%$ & Count & $\%$ & Count & $\%$ \\
\hline \multicolumn{11}{|c|}{ Radiologist vs nonradiologist } \\
\hline Radiologists & 48 & $80.0 \%$ & 55 & $83.3 \%$ & 52 & $76.4 \%$ & 56 & $66.7 \%$ & 69 & $77.5 \%$ \\
\hline Nonradiologists & 12 & $20.0 \%$ & 11 & $16.7 \%$ & 16 & $23.6 \%$ & 28 & $33.3 \%$ & 20 & $22.5 \%$ \\
\hline \multicolumn{11}{|l|}{ Degree } \\
\hline Both MD and $\mathrm{PhD}$ & 1 & $1.7 \%$ & 4 & $6.2 \%$ & 5 & $8.6 \%$ & 9 & $11.3 \%$ & 16 & $18.0 \%$ \\
\hline MD & 56 & $96.6 \%$ & 56 & $86.2 \%$ & 47 & $81.0 \%$ & 58 & $72.5 \%$ & 64 & $72.0 \%$ \\
\hline $\mathrm{PhD}$ & 2 & $3.4 \%$ & 5 & $7.6 \%$ & 6 & $10.4 \%$ & 10 & $12.5 \%$ & 8 & $8.9 \%$ \\
\hline Master of Science & 0 & $0.0 \%$ & 0 & $0.0 \%$ & 0 & $0.0 \%$ & 3 & $3.7 \%$ & 1 & $1.1 \%$ \\
\hline \multicolumn{11}{|l|}{ Institution } \\
\hline Multiple institutions & 17 & $28.3 \%$ & 15 & $22.7 \%$ & 19 & $27.9 \%$ & 43 & $51.2 \%$ & 51 & $34.5 \%$ \\
\hline Single institution & 43 & $71.7 \%$ & 51 & $77.3 \%$ & 49 & $72.1 \%$ & 41 & $48.8 \%$ & 38 & $65.5 \%$ \\
\hline \multicolumn{11}{|l|}{ Funding } \\
\hline Funded & 12 & $20.0 \%$ & 14 & $21.2 \%$ & 17 & $25.0 \%$ & 39 & $46.4 \%$ & 33 & $37.1 \%$ \\
\hline Unfunded & 48 & $80.0 \%$ & 52 & $78.8 \%$ & 51 & $75.0 \%$ & 45 & $53.6 \%$ & 56 & $62.9 \%$ \\
\hline \multicolumn{11}{|l|}{ Field } \\
\hline Brain & 13 & $21.7 \%$ & 26 & $39.4 \%$ & 30 & $44.8 \%$ & 28 & $33.7 \%$ & 33 & $39.8 \%$ \\
\hline Head and Neck & 24 & $40.0 \%$ & 7 & $10.7 \%$ & 9 & $13.4 \%$ & 14 & $16.9 \%$ & 13 & $15.7 \%$ \\
\hline IR-Vascular & 16 & $26.7 \%$ & 14 & $21.2 \%$ & 19 & $28.4 \%$ & 25 & $30.1 \%$ & 22 & $26.5 \%$ \\
\hline Peds & 6 & $10.0 \%$ & 13 & $19.7 \%$ & 2 & $3.0 \%$ & 10 & $12.0 \%$ & 5 & $6.0 \%$ \\
\hline PNS-Spine & 1 & $1.6 \%$ & 6 & $9.0 \%$ & 7 & $10.4 \%$ & 6 & $7.3 \%$ & 10 & $12.0 \%$ \\
\hline
\end{tabular}

Note:-IR indicates interventional radiology; PNS, peripheral nervous system.

Table 2: Distribution of radiologists versus nonradiologists in the field of neuro-IR

\begin{tabular}{lcc}
\hline Field & Nonradiologist (Count) & Radiologist (Count) \\
\hline Non-IR & 57 & 214 \\
Neuro-IR & 30 & 66 \\
\hline
\end{tabular}

Table 3: Regression model of predictor factors and association with radiology versus nonradiology

\begin{tabular}{lcccc}
\multicolumn{1}{c}{ Predictor Factor } & Exp(B) & \multicolumn{2}{c}{$95 \%$ Cl } \\
for $\operatorname{Exp}(\mathrm{B})$ & P Value \\
\hline $\begin{array}{l}\text { Funding (funded vs unfunded) } \\
\text { Degree (PhD vs MD) }\end{array}$ & 0.662 & 0.372 & 1.178 & .160 \\
Field & 0.826 & 0.351 & 1.947 & .663 \\
$\quad$ Head and neck & & & & \\
$\quad$ Brain & 1.911 & 1.012 & 3.611 & .019 \\
$\quad$ Spine & 2.551 & 0.860 & 7.564 & .091 \\
$\quad$ Neuro-IR & 1.269 & 0.696 & 2.315 & .437 \\
$\quad$ Pediatric & 6.758 & 1.900 & 24.035 & .003 \\
Year & & & & \\
$\quad 1998$ & & & & .029 \\
2003 & 2.856 & 1.295 & 6.299 & .009 \\
2008 & 2.271 & 1.065 & 4.843 & .034 \\
2013 & 1.601 & 0.819 & 3.128 & .169 \\
2018 & 2.414 & 1.232 & 4.732 & .010 \\
\hline
\end{tabular}

Note:- $\operatorname{Exp}(B)$ indicates exponential of the regression coefficient.

${ }^{a}$ Studies we are analyzing that were funded or non-funded.

\section{Funded versus Unfunded Research}

We found a concomitant increasing trend toward funded articles in the AJNR. Lim et $\mathrm{al}^{3}$ studied the publishing of funded original articles in 2 major American radiology journals, the American Journal of Roentgenology (AJR) and Radiology, between 2001 and 2010. They showed that only $26.9 \%$ (1758 of 6542) of original articles were funded, a proportion that is remarkably low in comparison with other specialties, but close to the $31.3 \%$ of $A J N R$ articles that we report herein. ${ }^{3}$ One study documented that $77 \%$ of the original articles published in the major medical and neurologic journals in 1991 were funded. ${ }^{4}$ While the trend in the AJNR is toward an increase in funded original articles, radiology literature still trails other specialties significantly in the publication of funded studies.

\section{Radiologist versus Nonradiologist Authorship in the AJNR}

In our study, we show that of the 367 original articles, radiologists were the first authors in $280(76.3 \%)$ articles, followed by neurosurgeons $(27,7.4 \%)$ and neurologists $(26,7.1 \%)$. Lim et $\mathrm{al}^{3}$ also evaluated the contributions of radiologists versus nonradiologists in original radiology articles and found that although radiologists still have the most prominent role in radiology research, $12.4 \%$ (811 of 6542 ) of articles had a nonradiologist as the first author, including $15.4 \%$ in Radiology (541 of 3571). ${ }^{3}$ One contributing factor to high number nonradiologist contributions was likely the growth in multidisciplinary collaborative studies among radiologists and clinicians from other medical specialties in which the first author was not a radiologist. Additionally, many nonradiologists who are performing radiology or radiology-related research may be choosing to submit their publications to radiology journals rather than clinical journals. This possibility may be particularly true in NIR, in which neurosurgeons and neurologists have a greater participation rate than diagnostic neuroradiologists. These trends indicate that radiology research is spreading throughout the clinical literature with more interplay between radiologists and nonradiologists. In summary, MDs and radiologists still dominate authorship in the AJNR; however, there are trends from 1998 to 2018 toward more $\mathrm{PhD}$-authored, multi-institutional, and funded articles. 
Disclosures: David Yousem—UNRELATED: Expert Testimony: Witness fees; Payment for Lectures Including Service on Speakers Bureaus: MRI Online, American College of Radiology; Royalties: Elsevier, Analytical Informatics Institute, money paid to individual.

\section{REFERENCES}

1. Emamzadehfard S, Eslami V, Yousem DM, et al. Disproportionate international contributions to subspecialties of neuroradiology in the American Journal of Neuroradiology. AJNR Am J Neuroradiol 2019;40:E3-4 CrossRef Medline

2. Fang FC, Casadevall A. NIH peer review reform: change we need, or lipstick on a pig? Infect Immun 2009;77:929-32 CrossRef Medline

3. Lim KJ, Yoon DY, Yun EJ, et al. Characteristics and trends of radiology research: a survey of original articles published in AJR and Radiology between 2001 and 2010. Radiology 2012;264:796-802 CrossRef Medline
4. Stein MD, Rubenstein L, Wachtel TJ. Who pays for published research? JAMA 1993;269:781-82 Medline

(1) S. Emamzadehfard Department of Radiology University of Texas Health Science Center

San Antonio, Texas

(1) A. Taree Icahn School of Medicine at Mount Sina New York, New York

(D) D.M. Yousem Johns Hopkins Medical Institution Baltimore, Maryland 